\title{
Descrição da fêmea e redescrição do macho de Macrosoma klagesi (Prout) (Lepidoptera, Hedyloidea, Hedylidae)
}

\author{
Gilcélia Melo Lourido ${ }^{1} \&$ Catarina da Silva Motta $^{2}$
}

\begin{abstract}
${ }^{1}$ Divisão do Curso de Pós-Graduação em Entomologia, Instituto Nacional de Pesquisas da Amazônia. Av. André Araújo, 2936, Petrópolis, 69060-001 Manaus-AM, Brasil. lourido@inpa.gov.br

${ }^{2}$ Coordenação de Pesquisas em Entomologia, Instituto Nacional de Pesquisas da Amazônia. motta@inpa.gov.br
\end{abstract}

\begin{abstract}
Description of the female and redescription of the male of Macrosoma klagesi (Prout) (Lepidoptera, Hedyloidea, Hedylidae). The female of Macrosoma klagesi (Prout, 1916) is described and illustrated for the first time based on individuals collected in the municipality of Presidente Figueiredo, state of Amazonas, Brazil. The male genital strutures are redescribed and illustrated.
\end{abstract}

KEYWORDS. Amazonas; geographical distribution; morphology; taxonomy.

RESUMO. Descrição da fêmea e redescrição do macho de Macrosoma klagesi (Prout) (Lepidoptera, Hedyloidea, Hedylidae). A fêmea de Macrosoma klagesi (Prout, 1916) é descrita e ilustrada pela primeira vez com base em indivíduos coletados no município de Presidente Figueiredo, estado do Amazonas, Brasil. A genitália do macho é redescrita e ilustrada.

PALAVRAS-CHAVE. Amazonas; distribuição geográfica; morfologia; taxonomia.

Macrosoma klagesi (Prout, 1916) (Lepidoptera, Hedyloidea, Hedylidae) foi descrita inicialmente no gênero Phellinodes Guenée, 1857, com base em um exemplar macho proveniente do município de Fonte Boa, estado do Amazonas, Brasil. O espécime foi coletado em maio de 1906 por S.M. Klages e encontra-se depositado no Natural History Museum, Londres (Prout 1916; Scoble 1990a; 1998).

Scoble (1986), ao fazer a revisão de Hedylidae, considerou Phellinodes sinônimo júnior de Macrosoma Hübner, 1818, único gênero reconhecido atualmente, no qual estão inseridas 35 espécies. Das espécies consideradas por Scoble (1990a, b, 1992, 1998), nove são conhecidas apenas pelos machos: $M$. klagesi, Macrosoma intermedia (Dognin, 1911), Macrosoma albifascia (Warren, 1904), Macrosoma albistria (Prout, 1916), Macrosoma uniformis (Warren, 1904), Macrosoma amaculata Scoble, 1990, Macrosoma albimacula (Warren, 1900), Macrosoma lamellifera (Prout, 1916), Macrosoma minutipuncta (Prout, 1916).

A ocorrência de $M$. klagesi foi registrada em três localidades do Peru: Pasco e Cuzco (Lamas \& Grados 1997) e região de Urubamba (Grados 1998); os autores não informam o sexo.

Lourido et al. (2008) obtiveram seis machos dessa espécie em coletas realizadas a $40 \mathrm{~m}$ de altura, em uma área de terra firme na Amazônia brasileira. Para os autores a presença destes lepidópteros no dossel da floresta representa um indício de que algumas espécies dessa família voam sobre as copas das árvores para dispersão, oviposição ou a procura de alimento.

Neste trabalho registram-se duas fêmeas e dois machos provenientes do município de Presidente Figueiredo, estado do Amazonas, representando o primeiro registro da fêmea de M. klagesi. A descrição da fêmea e a redescrição do macho foram realizadas, principalmente, com base na genitália.

\section{MATERIALE MÉTODOS}

Os espécimes de M. klagesi aqui estudados, incluindo aqueles registrados por Lourido et al. (2008), estão depositados na Coleção de Invertebrados do Instituto Nacional de Pesquisas da Amazônia sob os números: 42141, 42153, 42179, 42227, 42041 a 42045 e 42056.

As coletas noturnas foram realizadas em áreas de floresta primária, utilizando-se sempre um lençol branco iluminado alternando lâmpada mista de mercúrio e tungstênio e lâmpada de vapor de mercúrio, ambas de 250W.

Os espécimes foram medidos com auxílio de um paquímetro digital, tomando-se como medida da asa anterior, desde a base até o ápice. Para o comprimento do corpo, foi considerada a distância entre os palpos e a extremidade posterior do abdome.

A genitália de ambos os sexos foram preparadas pelo método usual, observadas em lâminas escavadas, utilizando glicerina como meio de inclusão, desenhadas sob câmara clara acoplada a um microscópio composto Leitz Wetzlar e acondicionadas em microtubos de polietileno com glicerina, anexados aos espécimes correspondentes.

As descrições da genitália seguem a nomenclatura de Klots (1970) e algumas adaptações de Mielke et al. (2004).

\section{RESULTADOS}

\section{Macrosoma klagesi (Prout)}

Fêmea (Fig. 1): Comprimento do corpo 15,36 e 15,54 mm.

Cabeça: Vértice e frontoclípeo brancos entremeados de tons acastanhados. Antenas filiformes. Palpos labiais castanhos com cerdas brancas na base do primeiro artículo.

Tórax: Face dorsal castanha entremeada de branco, tégulas 

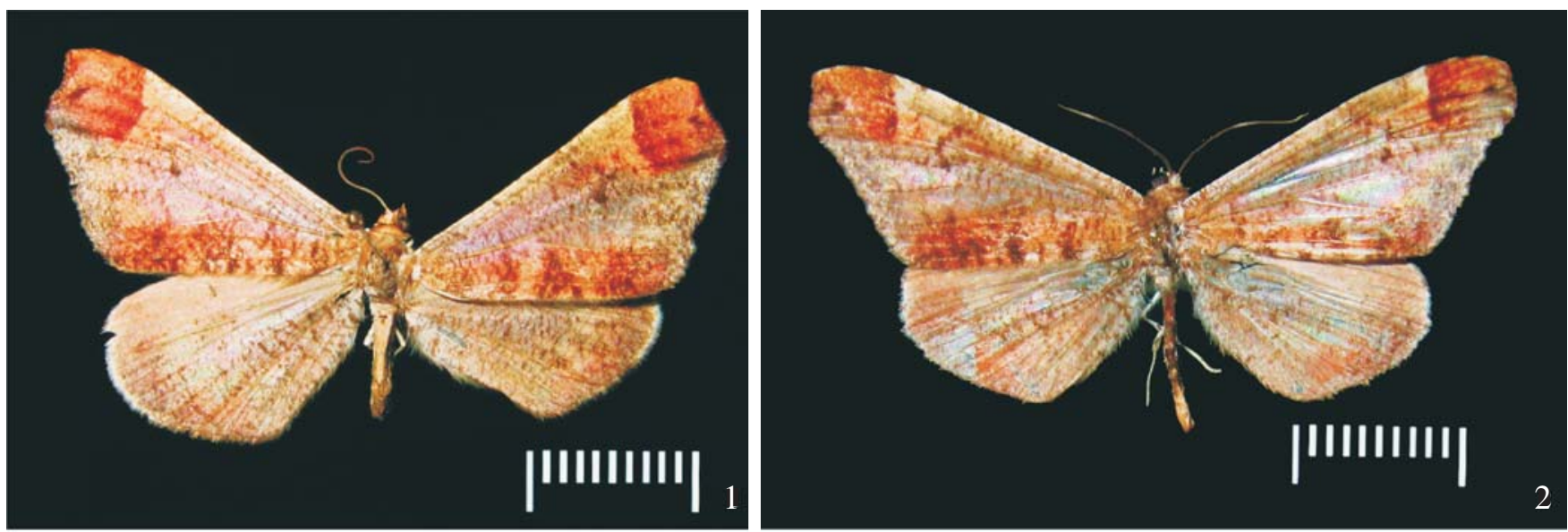

Figs. 1-2. Macrosoma klagesi (Prout): (1) fêmea; (2) macho. Escala: $10 \mathrm{~mm}$.

com cerdas longas de coloração branca na base e ápice acastanhado; face ventral branca. Asa anterior com comprimento de 22,35 e 23,84 mm; ápice emarginado. Face dorsal predominantemente castanha com mancha apical castanho-escura com ponto escuro próximo a margem distal; área semitransparente na região mediana, entremeada de pequenas manchas castanho-escuras, margem interna com faixa longitudinal castanho-escura, com aglomerados de escamas mais escuras formando faixas transversais. Asa posterior predominantemente castanha com área semitransparente na região mediana, escamas escuras ao longo desta mais concentradas na margem externa. Face ventral, em ambas as asas, mais clara, porém com padrão de coloração semelhante à dorsal. Frênulo com cerdas curtas. Pernas protorácicas predominantemente brancas com manchas transversais de escamas escuras nos segmentos tarsais. Pernas meso e metatorácicas com tíbias e tarsos amarelo pálido; parte interna da tíbia protorácica com epífise variando de amarela a castanha; esporões tibiais 0:2:2.

Abdome com face dorsal castanha; face ventral castanha com nuances brancas.

Genitália feminina em vistas ventral e lateral (Figs. 3, 4) com papilas anais recobertas por cerdas longas. Apófises posteriores mais longas que as anteriores. Lamela antevaginal constituída por duas barras transversais não fundidas ventralmente. Óstio semicircular. Antro cerca de um terço do comprimento do duto da bolsa. Duto seminal surgindo dorsalmente na extremidade proximal do antro. Corpo da bolsa copuladora com prolongamento na parte anterior, signo denticulado na lateral esquerda.

Macho (Fig. 2): comprimento do corpo variando de 16,78 a $18,36 \mathrm{~mm}$. Comprimento da asa anterior 21,49 a 22,86 mm. Padrão de coloração semelhante ao da fêmea, diferindo pela forma das asas anteriores com ápice reto quando comparado à fêmea, pelas asas posteriores com área vítrea próximo à base da célula discal e com uma pequena expansão no ramo cubital, pela presença de frênulo em forma de espinho visível e retináculo, pelas pernas anteriores mais longas que as meso e metatorácicas e pela presença de um pincel de cerdas acastanhadas nas tíbias protorácicas.

Genitália masculina (Figs. 5-8) com unco simples, subtriangular, ápice arredondado e projetado além das valvas. Unco e tegume com suave constrição em vista dorsal. Gnato em forma de alça, parte ventral com projeção central em forma de espátula e expansões laterais arredondadas. Juxta subtrapezoidal, em vista ventral. Saco desenvolvido, com projeção anterior mais longa que a distância entre os braços dorsais. Valvas subiguais e subtriangulares, ápice arredondado.

Material examinado: Fêmeas - BRASIL, Amazonas, Presidente Figueiredo, AM-240 (Estrada de Balbina), km 24, 02 00 ' $55^{\prime \prime} \mathrm{S} /$ 5949'40"W, 28-29/VII/2005, Lourido, G.M.; Xavier Filho, F.F.; Machado, R.J.P. col., Lençol/Vapor de mercúrio/BLB; idem, 09-10/IX/ 2007, G.M. Lourido, V.R. Alves, F.F. Xavier Filho; Machos - BRASIL, Amazonas, Presidente Figueiredo, AM-240 (Estrada de Balbina), km 24, 0200'55"S/5949'40"W, 26-27/VII/2005; Idem, Ramal, 28-29/ VII/2005; Manaus, ZF-2, km-14, Torre $40 \mathrm{~m}$ de altura, $2^{\circ} 35^{\prime} 21^{\prime \prime} \mathrm{S} /$ $60^{\circ} 06^{\prime} 55^{\prime \prime W}, 26 / X / 2003$, J.A. Rafael; F.F. Xavier Filho; A. Silva Filho col., Luz mista de mercúrio, lençol; idem, 19-20/III/2004, J.A. Rafael; C.S. Motta; J.T. Câmara; F.F. Xavier Filho; A. Silva Filho col., Luz mista de mercúrio, Luz negra BL e BLB; idem, 20-21/III/2004; idem, 19-20/V/2004, J.A. Rafael; S.F. Trovisco; F.F. Xavier Filho; A. Silva Filho; F. Baccaro col.; idem, 17-18/VII/2004, J.A. Rafael; C.S. Motta; S.F. Trovisco; F.F. Xavier Filho; J.M.F. Ribeiro col.; idem, 13-14/X/ 2004, J.A. Rafael; C.S. Motta; S.F. Trovisco; F.F. Xavier Filho; A. Silva Filho col.

\section{DISCUSSÃO}

A fêmea pôde ser associada ao macho de M. klagesi pela semelhança no padrão de coloração e pela ocorrência para o mesmo local de coleta, município de Presidente Figueiredo, e para o mesmo período em que o macho foi coletado.

Prout (1916) descreveu a espécie com base no padrão de coloração das asas e a comparou a Macrosoma cascaria (Schaus, 1901). No entanto, M. cascaria possui asa anterior com ápice proeminente quando comparado ao de M. klagesi.

Scoble (1990b) apresentou uma fotografia de M. klagesi e desenho esquemático da genitália masculina em vista lateral e 

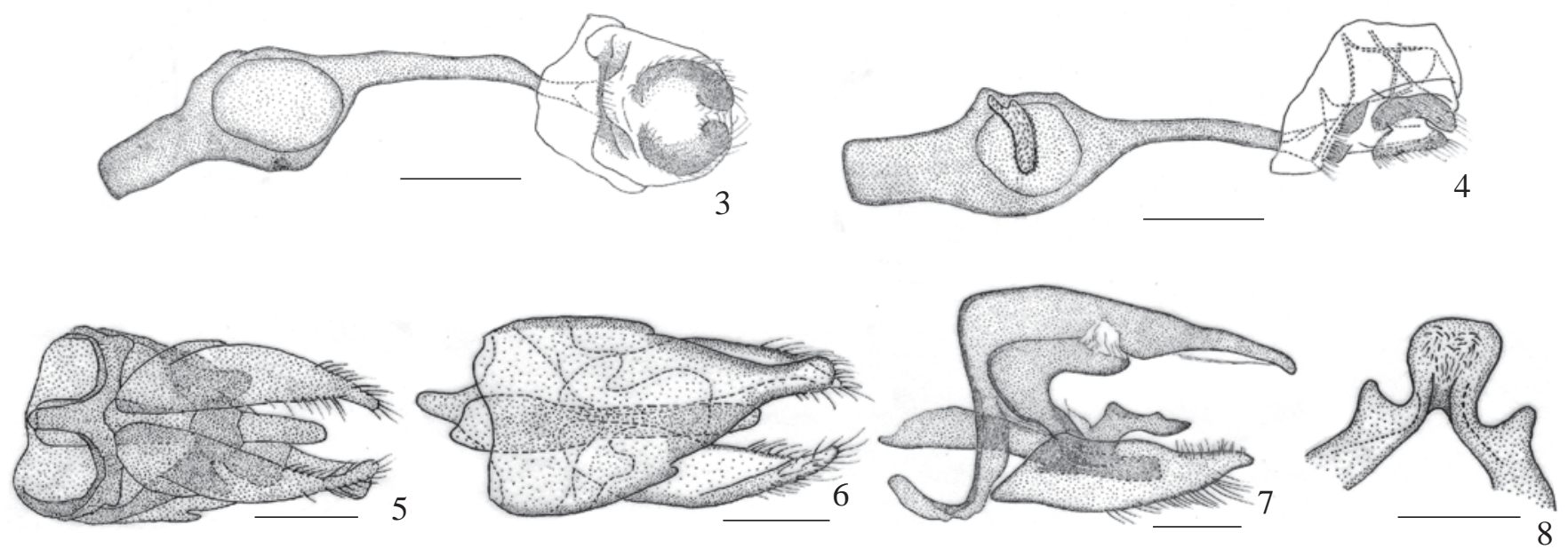

Figs. 3-8. Macrosoma klagesi (Prout): (3) genitália feminina vista ventral; (4) vista lateral; (5) genitália masculina vista ventral; (6) vista dorsal; (7) vista lateral (8) detalhe do gnato. Escalas: genitálias femininas $1 \mathrm{~mm}$; genitálias masculinas $0,5 \mathrm{~mm}$.

a considerou similar ao macho de Macrosoma nigrimacula (Prout, 1916), diferindo desta pela asa anterior com mancha apical proeminente e pela genitália masculina com processo anterior do saco mais curto e formas diferenciadas das valvas e do gnato. M. nigrimacula apresenta dimorfismo sexual, pois a fêmea tem na asa anterior uma mancha subapical branca, o que a diferencia da fêmea de $M$. klagesi. Além disso, a genitália feminina de M. klagesi, com corpo da bolsa copuladora com prolongamento na parte anterior, a distingue das demais espécies em que as fêmeas são conhecidas.

O período de ocorrência de $M$. klagesi foi registrado para os meses de março, maio, julho, setembro e outubro. A distribuição parece restrita às Amazônias brasileira e peruana, uma vez que só há registros para essas regiões. No entanto, não se descarta a possibilidade destes resultados estarem relacionados à falta de coletas em outra áreas e/ou de publicações a respeito do grupo.

Agradecimentos. Ao Francisco Felipe Xavier Filho, técnico em entomologia/INPA, pela ajuda com as coletas em Presidente Figueiredo.

\section{REFERÊNCIAS}

Druce, H. 1893. Geometridae, Hedylinae, p. 178-179. In: R. H. Porter (ed.). Biologia Centrali-Americana. Insecta. LepidopteraHeterocera, vol. II, iv+622 p.

Grados, J. 1998. Biodiversity Assessment of the Hedylidae of the Lower Urubamba Region, Peru, p. 119-120. In: A. Alonso; F. Dallmeier;
P. Campbell (eds.). Urubamba: The Biodiversity of a Peruvian Rainforest. SI/MAB Series \#7. Smithsonian Institution, Washington, DC, 204 p.

Klots, A. B. 1970. Lepidoptera, p. 115-130. In: S. L. Tuxen (ed.) Taxonomist's glossary of genitalia in insects. Munksgaard, Copenhagem, $213 \mathrm{p}$.

Lamas, G. \& J. Grados. 1997. Sinopsis de los Hedylidae (Lepidoptera) del Peru. Revista Peruana de Entomologia 40: 107-109.

Lourido, G. M.; C. S. Motta; J. A. Rafael; J. W. Morais \& F. F. Xavier Filho. 2008. Hedylidae (Lepidoptera: Hedyloidea) coletados à luz a 40 metros de altura no dossel da floresta da Estação Experimental de Silvicultura Tropical em Manaus, Amazonas, Brasil. Acta Amazonica 38: 329-332.

Mielke, C. G. C.; O. H. H. Mielke \& M. M. Casagrande. 2004. Estudo comparado da morfologia externa de Zaretis itys itylus (Westwood) e Agrias claudina annetta (Gray) (Lepidoptera, Nymphalidae, Charaxinae). III. Abdome. Revista Brasileira de Zoologia 21 905-912.

Prout, L. B. 1916. New Neotropical Geometridae. Novitates Zoologicae 23: 151-190.

Prout, L. B. 1932. The American Geometridae, p. 16-20. In: A. Seitz (ed.). The Macrolepidoptera of the world vol. III, $144 \mathrm{p}$.

Scoble, M. J. 1986. The structure and affinities of the Hedyloidea: a new concept of the butterflies. Bulletin of the British Museum Natural History (Entomology) 53: 251-286.

Scoble, M. J. 1990a. A catalogue of the Hedylidae (Lepidoptera: Hedyloidea), with descriptions of two new species. Entomologica Scandinavica 21: 113-119.

Scoble, M. J. 1990b. An identification guide to the Hedylidae (Lepidoptera: Hedyloidea). Entomologica Scandinavica 21: 121158.

Scoble, M. J. 1992. Guia de las mariposas hedylidas de Costa Rica (Lepidoptera: Hedylidae). INBIO, Heredia-Costa Rica, 30p. Scoble, M. J. 1998. Hedylidae. In: J. B. Heppner (ed.). Lepidopterorum Catalogus 93: viii+8 p.

Recebido em 26/08/2008; aceito em 13/10/2008 